\title{
Developing Indicators Based on Life Cycle Sustainability Impact Assessment for Strategic Environmental Assessment
}

\author{
Kevin Fong-Rey Liu, Shih-I. Tsai, and Dana Aswara
}

\begin{abstract}
Strategic environmental assessment (SEA) is a systematic decision support process by which environmental, economic and social considerations are considered effectively in policy, plan and programme. Taiwan SEA involves eight categories and 33 criteria. One of the objectives of SEA is to establish indicators and to select the most appropriate alternative of possible policies. Once the indicators are established, a comprehensive evaluation of each alternative can be conducted to determine whether the main policy is the most preferred. A total of 28 Taiwan SEA cases, from 2001 to 2016, are reviewed policy EIA specifications from 1990 to 105 and the result shows that most of the cases did not have a clear comprehensive assessment method. Another type of 7 cases has a clear and comprehensive assessment method, which is AHP. However, if their indicators are classified according to the sustainable development model, Drivers-Pressures-StateImpacts- Response, the relationship between indicators should be networked, non-independent, causal, and some indicators are midpoint and dome are endpoints, they are therefore not applicable to AHP because of double counting. Moreover, the impact of a policy is extensive, in addition to the direct effects on the regions in which the policy is implemented, the indirect and cumulative effects on the region and even the global should be considered. Therefore, the life cycle sustainability assessment (LCSA), involving Life cycle assessment (LCA), Life cycle costing (LCC) and Social life cycle assessment (S-LCA), is used as the impact assessment tool for SEA because it can establish the impact pathway of its life cycle sustainability impact assessment (LCSIA) to clarify its causal relationship and midpoints and endpoints. Based on the midpoint indicators, the indicators for SEA are developed.
\end{abstract}

Index Terms-Strategic environmental assessment, life cycle sustainability impact assessment, DPSIR framework.

\section{INTRODUCTION}

Strategic environmental assessment (SEA) is a systematic decision support process, aiming to ensure that environmental and possibly other sustainability aspects are considered effectively in policy, plan and programme making. According to Taiwan government SEA instructions, the impact considered in a SEA should include environmental capacity, natural ecology and landscape, human health and safety, the use of land resources, water resources system and its use, cultural assets, international environmental norms,

Manuscript received August 15, 2018; revised May 13, 2014.

K. F. R. Liu and S. I. Tsai are with the Department of Safety, Health and Environmental Engineering, Ming Chi University of Technology, New Taipei City, Taiwan 24301, ROC (corresponding author; e-mail: kevinliu@mail.mcut.edu.tw).

D. Aswara is with the Faculty of Science and Technology, Universitas Pahlawan Tuanku Tambusai Bangkinang, Riau Province, Indonesia. society and economy. One of the objectives of SEA is to establish indicators [1], [2] and to select the most appropriate alternative of possible policies. Once the indicators are established, a comprehensive evaluation of each alternative can be conducted to determine whether the main policy is the most preferred. There are some issues in this study. Firstly, the majority $(75 \%)$ of the domestic SEA cases do not has a comprehensive assessment and thereby they do not provide a scientific decision-making tool to support the main policy surpassing other alternatives. Secondly, although a small part $(25 \%)$ of the domestic SEA cases are evaluated comprehensively, but some indicators such as pollutant emissions and resource consumption are stress indicators within DPSIR model, which are difficult to understand their impacts. Thirdly, if midpoints/endpoints in LCSA are used as impact indicator for SEA, some indicators of LCC and S-LCA fail to take into account the impact of the economy and society at the regional or national level.

Life cycle assessment (LCA) is a damage-oriented impact assessment method, it applies midpoints/endpoints as its environmental impact indicators. In recent years, it has been gradually applied to Environmental Impact Assessment (EIA). In Taiwan, seven cases of domestic SEA using AHP as the overall comprehensive decision-making process, also utilized LCA as a part of environmental indicators. Nevertheless, the Life cycle sustainability assessment (LCSA) involves Life cycle assessment (LCA), Life cycle costing (LCC) and Social life cycle assessment (S-LCA), which considering environmental, economic and social aspects at the same time. Compared to LCA, LCSA is the more suitable impact assessment tool for SEA.

The literature on life cycle assessment (LCA) applied to policy environmental impact assessment (SEA) are discussed as follows. Stripple and Erlandsson [3] discussed the applicability of LCA to SEA. Lundie et al. [4] used LCA for policy planning in the Sydney water system. Loiseau et al. [5] examined nine analytical tools suitable for SEA, including human and environmental risk assessment (HERA), ecological footprint (EF), material flow analysis (MFA), substance flow analysis (SFA), and physical input- Output table (PIOT), ecological network analysis (ENA), exergy, emergy, and life cycle assessment (LCA) indicate that LCA is an analytical tool for SEA. Björklund [6], based on Swedish urban energy planning, examines the applicability of LCA as an analytical tool for SEA, and concludes that LCA can provide a system-wide perspective and architecture that contributes to SEA. In order to achieve an environmental assessment of policy planning for land use, Loiseau et al. [7] 
proposed a revised LCA framework. Adamczyk and Dzikuć [8] used LCA to assess the environmental impact of four power plants in Poland as a reference for future energy policies. Bidstrup et al. [9] argue that spatial planning should consider systemic impact, including global, indirect, and cumulative effects. Electricity demand in the Republic of Mauritius is growing rapidly. Most of the electricity is generated from fossil fuels, using coal, fuel, bagasse and hydropower. Brizmohun et al. [10] used LCA to evaluate these types of power generation. The effect of carbon emissions on the environment. Nikkhah et al. [11] evaluated $\mathrm{SO} 2, \mathrm{CO} 2, \mathrm{NH} 3$ and other pollutants emitted during the production of kiwifruit in Guilan, Iran, and analyzed the environmental impacts using the LCA and Cobb-Douglas (CD) models.

This paper has the following objectives: (1) to review literature to find relevant indicators and then classify them into environmental, economic and social groups; (2) to define impact indicators as the key indicators in the DPSIR model; and (3) to modify life cycle sustainability assessment (LCSA) as the comprehensive assessment method for SEA. According to the index system developed in this study, the 28 SEA cases are reviewed and quite few cases meet the recommended indicators in this study. Finally, the evaluation framework of two SEA cases are detailed suggested.

\section{Methods AND MATERIALS}

\section{A. Life Cycle Sustainability Assessment (LCSA)}

Environmental life cycle assessment methods are widely used to judge environmental issues for sustainable development, but the use of similar methods to assess economic (life cycle costs) and social (social life cycle assessment) aspects is still limited. The developments of the two aspects (economic and social) are very important because they allow SEA based on sustainability assessments. The two aspects can develop based on ISO 14040 [12], which are scoping, inventory analysis, impact assessment and interpretation. Klöpffer [13] turned this idea into a conceptual formula:

LCSA $=$ (environmental) $\mathrm{LCA}+\mathrm{LCC}+\mathrm{S}-\mathrm{LCA}$

LCSA: Life cycle sustainability assessment

LCA: Life cycle assessment

LCC: Life cycle costing

S-LCA: Social life cycle assessment

The study redefines the formula as

$$
\begin{aligned}
\mathrm{LCSA} & =\text { environmental LCA } \\
& + \text { Economic LCA } \\
& + \text { Social LCA }
\end{aligned}
$$

The impact pathway of life cycle sustainability impact assessment (LCSIA) is thereby established to clarify its causality and midpoint and endpoint.

\section{B. DPSIR Sustainability Model}

In recent years, the Statistical Office of the European
Union (EUROSTAT) and the European Environment Agency (EEA) have expanded the early pressure-state-response model (PSR) of OECD to the driving-force-pressure-state-impact-response model (DPSIR, Fig. 1), in which the indicators related to driving force, pressure, and response are developed by EUROSTAT, and the state and impact are developed by EEA.

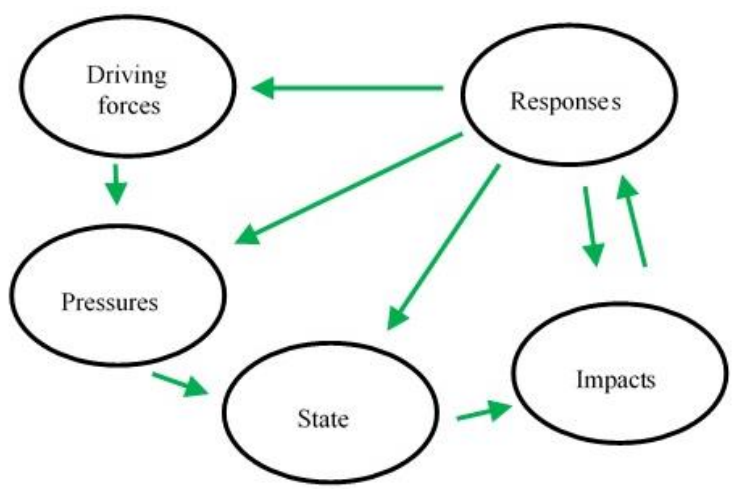

Fig. 1. Driving-force-pressure-state-impact-response model.

1) Drivers: Socio-economic sectors that fulfill human needs for food \& raw materials, water, shelter, health, culture, and security. Some socio-economic sectors do not directly fulfill human needs, but instead build and maintain the socio-economic infrastructure.

2) Pressures: Activities of the socio-economic drivers that exert positive or negative pressure on the state of ecosystems and human health.

3) State: Status of the abiotic (physical \& chemical) and biological (humans and other biota) components of the ecosystem. Chemical, physical and biological processes interact to affect different ecosystem components (e.g. chemicals, biological species) that can be measured by their attributes (metrics of quantity or quality). All biota incorporate community and population attributes, but human condition also incorporates individual-level and subpopulation-level attributes.

4) Impact: Changes in the quality and functioning of the ecosystem or human condition have an impact on the welfare (well-being) of humans. Ecosystem services, in particular, are the benefits that ecosystems can provide. Other factors, such as human health, habitat, \& behavior also contribute to human well-being.

5) Response: Responses are actions taken by groups or individuals in society and government to prevent, compensate, ameliorate or adapt to changes in well-being due to the state of the environment or condition of human health.

\section{RESUlTS AND DISCUSSION}

After reviewing related literatures, this study proposes the impact pathway of environmental, economic and social aspects, as shown in Fig. 2. It has four layers. The first layer is the state after carrying out the policy, for example, the emission. The second layer is the midpoint impact, a short term or direct influence causing by the change of the state. For example, emissions will result in the climate change, respiratory effects, cancer or non-cancer, photochemical 
ozone formation, aquatic eutrophication, terrestrial acidification, terrestrial and aquatic ecotoxicity. The third layer is the endpoint impact, a long term or indirect influence causing by the midpoint effects. For example, climate change, respiratory effects, cancer or non-cancer, and photochemical ozone formation will damage human health. On the other hand, climate change, aquatic eutrophication, terrestrial acidification, terrestrial and aquatic ecotoxicity will damage ecosystem. The midpoint impact will thereby keep changing the state. For example, the development of economy will emit more pollutants. Therefore, the detail indicators based on the DPSIR causal relationship are developed, as shown in Fig. 2. Ultimately, the last layer is the sustainability, which is a combination of all midpoint impacts and is accordingly used to choose the best policy in SEA process.

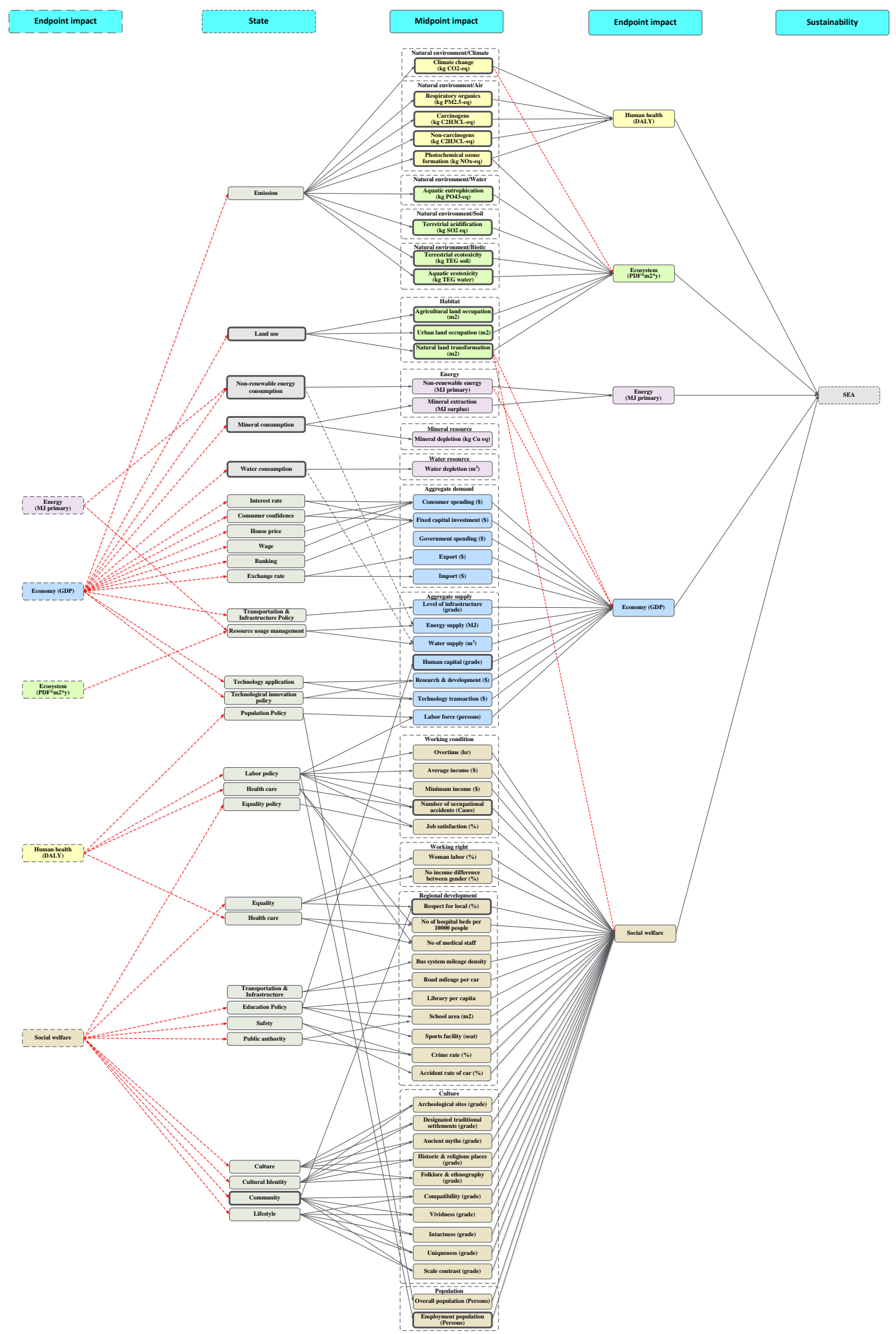

Fig. 2. Indicator and impact pathway. 
According to the proposed indicators and the impact pathway, the 28 Taiwan SEA cases are investigated to check whether they comply to the proposed indicators, as shown in TABLE I. The result shows the majority of the existing SEA is not compatible with the suggested indicators primarily because they are based on the state indicators rather than midpoint indicators proposed by the study.

TABLE I: COMPLIANCE OF 28 SEA CASES TO PROPOSED INDICATORS

\begin{tabular}{|c|c|c|}
\hline No. & Case & $\begin{array}{l}\text { No of indicators complying } \\
\text { to the proposed indicators }\end{array}$ \\
\hline 1 & $1050220 \mathrm{~A}$ & 2 \\
\hline 2 & $1050110 \mathrm{~A}$ & 2 \\
\hline 3 & $1050020 \mathrm{~A}$ & 1 \\
\hline 4 & $1030020 \mathrm{~A}$ & 2 \\
\hline 5 & 1021470A & 1 \\
\hline 6 & 1021010A & 1 \\
\hline 7 & 1020110A & 2 \\
\hline 8 & $1020040 \mathrm{~A}$ & 1 \\
\hline 9 & 1011430A & 3 \\
\hline 10 & 1011410A & 3 \\
\hline 11 & $1010070 \mathrm{~A}$ & 3 \\
\hline 12 & $1001430 \mathrm{~A}$ & 3 \\
\hline 13 & $1000440 \mathrm{~A}$ & 3 \\
\hline 14 & $1000310 \mathrm{~A}$ & 7 \\
\hline 15 & $1000210 \mathrm{~A}$ & 14 \\
\hline 16 & $1000130 \mathrm{~A}$ & 10 \\
\hline 17 & 0991670A & 1 \\
\hline 18 & 0991400A & 1 \\
\hline 19 & 0991220A & 15 \\
\hline 20 & 0991100A & 2 \\
\hline 21 & 0990010A & 3 \\
\hline 22 & 0970780A & 4 \\
\hline 23 & 0970590A & 3 \\
\hline 24 & 0950460A & 0 \\
\hline 25 & 0920590A & 2 \\
\hline 26 & 0910630A & 1 \\
\hline 27 & 0901420A & 0 \\
\hline 28 & 0901410A & 2 \\
\hline
\end{tabular}

\section{CONCLUSION}

The innovation of this study is to systematically consider the full effect (regional, global, indirect and cumulative), with an improved life cycle sustainability assessment (LCSA) as a comprehensive assessment tool for SEA, including environmental life cycle assessment, economic life cycle assessment and social life cycle assessment. It is mainly to establish the impact pathway of its life cycle sustainability impact assessment (LCSIA) to clarify its causal relationship and midpoints and endpoints. Based on the midpoint indicators, the indicators for SEA are proposed. There are 12 categories and 57 indicators. The existing Taiwan SEA are based on the state indicators rather than midpoint indicators proposed by the study. The challenge of using the indicators are the data of some of them is difficult to collect. In practical, the indicators can be adapted based on the data availability. Since the indicators exist some extent of causal relationship the future study is suggested to consider the dynamics of the system..

\section{REFERENCES}

[1] A. Donnelly, M. Jones, T. O'Mahony, and G. Byrne, "Selecting environmental indicator for use in strategic environmental assessment," Environmental Impact Assessment Review, vol. 27, no. 2, pp. 161-175, 2007.

[2] J. Gao, L. Kørnøv, and P. Christensen, "Do indicators influence communication in SEA? Experience from the Chinese practice," Environmental Impact Assessment Review, vol. 43, pp. 121-128, 2013.

[3] H. Stripple and M. Erlandsson, "Methods and possibilities for application of life cycle assessment in strategic environmental assessment of transport infrastructures," Building Environmental Assessment Consensus on the Transeuropean Transport Network (BEACON), I. S. E. R. Institute, 2004.

[4] S. Lundie, G. M. Peters, and P. C. Beavis, "Life cycle assessment for sustainable metropolitan water systems planning," Environ Sci Technol, vol. 38, pp. 3465-3473, 2004.

[5] E. Loiseau, G. Junqua, P. Roux, and V. Bellon-Maurel, "Environmental assessment of a territory: an overview of existing tools and methods," J Environ Manage, vol. 112, pp. 213-225, 2012.

[6] A. Björklund, "Life cycle assessment as an analytical tool in strategic environmental assessment. Lessons learned from a case study on municipal energy planning in Sweden," Environ Impact Assess Rev. vol. 32, pp. 82-87, 2012.

[7] E. Loiseau, P. Roux, G. Junqua, P. Maurel, and V. Bellon-Maurel, "Adapting the LCA framework to environmental assessment in land planning," The International Journal of Life Cycle Assessment, vol. 18, pp. 1533-1548, 2013.

[8] J. Adamczyk and M. Dzikuć, "The analysis of suppositions included in the Polish Energetic Policy using the LCA technique - Poland case study," Renewable and Sustainable Energy Reviews, vol. 39, pp. 42-50, 2014.

[9] M. Bidstrup, M. Pizzol, and J. H. Schmidt, "Life cycle assessment in spatial planning - A procedure for addressing systemic impacts," Journal of Cleaner Production, vol. 91, pp. 136-144, 2015.

[10] R. Brizmohun, T. Ramjeawon, and A. Azapagic, "Life cycle assessment of electricity generation in Mauritius," Journal of Cleaner Production, vol. 106, pp. 565-575, 2015.

[11] A. Nikkhah, B. Emadi, H. Soltanali, S. Firouzi, K. A. Rosentrater, and M. S. Allahyari, "Integration of life cycle assessment and Cobb-Douglas modeling for the environmental assessment of kiwifruit in Iran," Journal of Cleaner Production, vol. 137, pp. 843-849, 2016.

[12] ISO14040, "Environmental management-Life cycle assessment Principles and framework," International Organization for Standardization, 2006.

[13] W. Klöpffer, "Life cycle sustainability assessment of products," Int J Life Cycle Assess, vol. 13, no. 2, pp. 89-95, 2008.

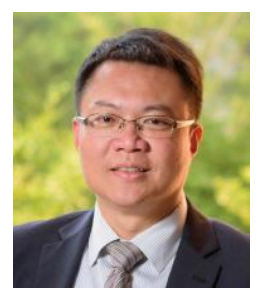

Kevin Liu received the Ph.D. degree in 1998, in civil engineering from National Central University, Taiwan. Currently, he is a professor in the Department of Safety, Health and Environmental Engineering, Ming Chi University of Technology, Taiwan. His research interest is the use of decision analysis and artificial intelligence techniques to environmental management issues. 